\title{
TOTAL AGENESIS OF THE CORPUS CALLOSUM IN A PATIENT WITH CHILDHOOD-ONSET SCHIZOPHRENIA
}

\author{
Jaime Eduardo Cecilio Hallak', José Alexandre de Sousa Crippa', \\ Joel Porfírio Pinto', João Paulo Machado de Sousa', \\ Clarissa Trzesniak', Serdar Murat Dursun², Phillip McGuire3, \\ John Francis William Deakin², Antonio Waldo Zuardi'
}

\begin{abstract}
The hypothesis that schizophrenia involves aberrant inter-hemispheric communication has a long pedigree, however its precise role remains unclear. We therefore report the case of a total agenesis of the corpus callosum in a 21-year-old man with childhood-onset schizophrenia. The presence of schizophrenia with very early onset on absence of corpus callosum offers an opportunity to examine neurodevelopmental model and theories regarding to interhemispheric communication in the pathogenesis of psychosis.
\end{abstract}

KEY WORDS: schizophrenia, corpus callosum, agenesis.

\begin{abstract}
Agenesia completa de corpo caloso em um paciente com esquizofrenia de início na infância
RESUMO - A hipótese que a esquizofrenia envolve comunicação inter-hemisférica aberrante possui longa tradição, entretanto seu papel permanece incerto. Nós relatamos um caso de agenesia total do corpo caloso em um homem de 21 anos portador de esquizofrenia de início na infância. A associação de esquizofrenia de início precoce na ausência de corpo caloso oferece uma oportunidade para exame do modelo neurodesenvolvimental e de teorias que envolvem a comunicação interemisférica na patogênese da psicose.
\end{abstract}

PALAVRAS-CHAVE: esquizofrenia, corpo caloso, agenesia.

There has been much interest in the idea that schizophrenia involves abnormalities of callosal function and inter-hemispheric transfer of information. We report a patient whose symptoms of schizophrenia occurred at a young age despite the complete absence of a corpus callosum.

The corpus callosum (CC) is the largest white matter tract in the brain. It connects most bilateral homologous regions of cortex and carries information between them ${ }^{1,2}$. It is made up mostly of glutamatergic fibres, which become progressively myelinated with age. The development of the CC is associated with the formation of the hippocampus and cingulate cortex, who are implicated in the pathophysiology of schizophrenia. However, whether the CC is abnormal in patients with schizophrenia is unclear ${ }^{3.4}$. The incidence of agenesis is difficult to estimate because is rare ${ }^{5-7}$ and not routinely detected. It has been estimated at $0.004 \%$ to $2.64 \%{ }^{1,5}$. Andermann noted the association between agenesis of the corpus callosum (ACC), mental retardation, peripheral neuronopathy and psychosis ${ }^{8}$ (Andermann's syndrome). More recently, Taylor and David ${ }^{9}$ analysed data provided by the British Neurological Surveillance Unit, and found that two thirds of patients with agenesis had neurological disturbances, such as epilepsy, and a third had one or more of intellectual impairment, a psychiatric diagnosis and obstetric complications at birth. However, only three cases involved diagnosis of psychosis. In most cases accomplished by schizophrenia the agenesis is partial, involving the anterior part of the $\mathrm{CC}^{3,10,11}$. Schizophrenia has been described in association with pure complete agenesis in 5 case reports, usually accompanied by another brain malformations ${ }^{3,5,10,11}$. Its symptoms occurred in adulthood and there were no particular psychopathological features. Given the rarity of ACC, it is thought that these cases may represent an association with schizophrenia. As we know,

'Department of Neurology, Psychiatry and Psychological Medicine; Ribeirão Preto Medical School, University of São Paulo, Ribeirão Preto SP, Brazil; ${ }^{2}$ Neuroscience and Psychiatry Unit, University of Manchester, Manchester, UK; ${ }^{3}$ Department of Psychological Medicine, Institute of Psychiatry, London, UK.

Received 18 July 2007, received in final form 18 September 2007. Accepted 9 October 2007.

Dr. Jaime Eduardo Cecilio Hallak - Hospital das Clínicas / $3^{\circ}$ andar / Campus Universitário - Avenida Bandeirantes 3900 - $14048-900$ Ribeirão Preto SP - Brasil . E-mail: jhallak@fmrp.usp.br 
childhood-onset schizophrenia and complete ACC has not been reported before.

\section{CASE}

A 21-year-old, right-handed male with eight years of education, whose gestation and birth appear to have been normal, presented at age nine with persecutory and reference delusions, auditory hallucinations, thought disorder and aggressiveness, and was diagnosed as having disorganized schizophrenia. The patient's family had no familiar history of psychiatric or neurological disorders, and provided written informed consent for this publication. He has since had five inpatient admissions and his sociocultural level of functioning was low. Treatment with typical antipsychotics (haloperidol, chlorpromazine) only slightly improved his psychotic symptoms. He presented to the Ribeirão Preto Medical School Hospital and the diagnosis of disorganized schizophrenia was confirmed using the Structured Clinical Interview ${ }^{12}$ for the Diagnostic and Statistical Manual of Mental Disorder, Fourth Edition ${ }^{13}$. He had no neurological symptoms or signs. In view of his history and poor response to treatment, further laboratory investigations were carried out. Complete ACC was detected on CT scan, without other abnormality. All serological tests were normal (Anti-HIV, VDRL, Machado-Guerreiro reaction and toxoplasmosis) .

Magnetic resonance images (MRI) were obtained on a 1.5 T Magnetom scanner (Siemens, Germany), revealing a total ACC (Figure A, B, C).

An electroencephalogram was abnormal, showing nonspecific slow waves in the occipital parietal region. Neuropsychological tests indicated a low current IQ (70) and impaired executive function, what may be attributed to his low educational level.

The patient failed to respond to a series of different antipsychotics (sulpiride, risperidone, olanzapine). Augmentation of antipsychotics with lithium, carbamazepine, valproate, or benzodiazepines was also ineffective. Unfortunately, his family disapproved the use of clozapine. He remains symptomatic.

\section{DISCUSSION}

The study of schizophrenia with very early onset offers an opportunity to examine neurodevelopmental model of schizophrenia. Although clinically similar to later onset schizophrenia, this population exhibits greater premorbid impairments and a more chronic course of illness, possibly due to a more severe genetic and/or environmentally determined disturbance of brain development ${ }^{14}$. Impaired intelligence disturbances are very common in cases of callosal agenesis, probably because of this neurodevelopmental insult ${ }^{3}$. Several cases with some degree of CCA combined with psychotic symptoms have been reported, but this is the first report of early onset schizophrenia. This finding support the neurodevelopmental models of schizophrenia, which may suggest the more severe the brain dysgenesis, the earlier the onset of psychotic symptoms and refractory to pharmacological treatments.

Recent studies have shown that the midline brain structures are poorly developed in schizophrenia ${ }^{15,16}$. Schizophrenia can be associated with macroscopic abnormalities on MRI scans, such as cavum septum pellucidum, and these may reflect a perturbation of brain development. These abnormalities seem to be commoner in male patients and in those with an early onset of psychosis, as in this case. CCA can be seen as an extreme example of such a neurodevelopmental anomaly. ACC could be associated with schizophrenia because abnormal callosal or interhemispheric function is central to the pathogenesis of schizophrenia. Alternatively, ACC could indicate the presence of a more general structural abnormality that predisposes to schizophrenia through normal development.

The literature on abnormalities of the CC in schizo-
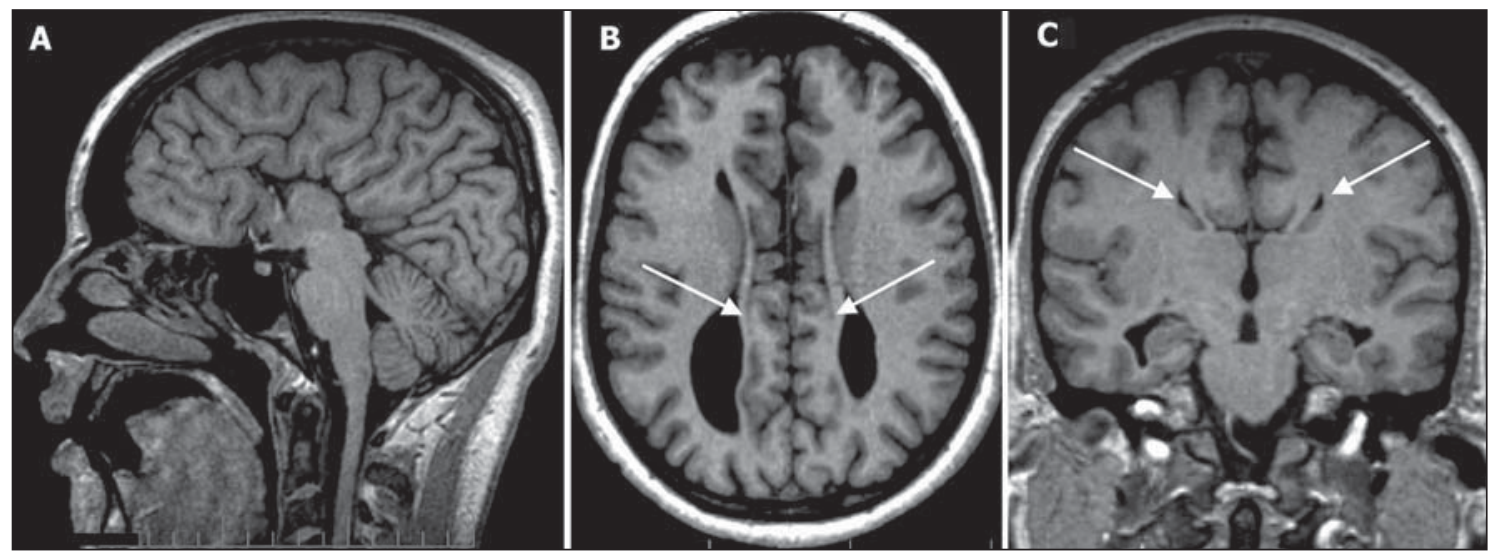

Figure. (A) Midsagittal view demonstrating complete agenesis of the corpus callosum; (B) Axial view demonstrating the presence of the non decussating fibre bundles of Probst (medial to the bodies of lateral ventricles - white arrows); (C) Coronal view demonstrating the classic "bat wings" appearance of the lateral ventricles - white arrows. 
phrenia is inconclusive, with some studies reporting enlargement and others reductions in volume. Bigelow and Rosenthal ${ }^{15}$ reported that patients with schizophrenia have thicker corpora callosum than those of normals, what were replicated by Coger and Serafetidines ${ }^{16}$ showing that the earlier the age of onset, and the more negative symptoms, the thicker was the corpus callosum. A thinner corpus callosum was associated with a later age of onset and more positive symptoms.

Jacobsen et al..$^{14}$ reported that CC was relatively larger in childhood onset schizophrenia, consistent with previous findings with chronic adult schizophrenia supporting continuity between childhood and later onset forms of this disorder. However, enlargement of the anterior $C$ does not appear to be essential for the development of early onset schizophrenia since our subject had complete agenesis and yet developed positive symptoms from the age of 9 years. Reinforcing this, many studies have been inconclusive about what kind of callosal alteration would be typical in schizophrenia ${ }^{2,17}$.

Abnormal inter-hemispheric communication has been demonstrated in a number of neuropsychological and neurophysiological studies in schizophrenia and in children at risk for schizophrenia ${ }^{14,16,18}$. The greater prevalence of partial CCA in patients with schizophrenia relative to controls suggests that abnormal development of this principal interhemispheric comissure may contribute to schizophrenic pathology, including aberrant interhemispheric communication ${ }^{1,5}$. Indeed a plausible account of passivity phenomena and hallucinations holds that right hemisphere generated speech and movements are experienced by the dominant and conscious left hemisphere as hallucinations and passivity phenomena.

Dysfunctional information transfer between the two hemispheres have been described in schizophrenia ${ }^{1,19}$. Other theories have suggested that increased inter-hemispheric communication may underlie symptoms of schizophrenia ${ }^{20}$. The presence of schizophrenia in the absence of CC poses difficulties for theories that postulate interhemispheric hyperconnectivity'. However, it could be argued that ACC might predispose to abnormal and excessive inter-hemispheric communication through the anterior commissure which interconnects ventral frontal and anterior temporal cortex. $\mathrm{Crow}^{21}$ developed the concept of 'misconnectivity', in which he reported that the variability of cortico-cortical connections in schizophrenia must be located in those callosal fibres pathways that connect areas of cortex that are assimetrically distributed between the two hemispheres. According to Crow ${ }^{21}$, psychosis and language have common origins. The mechanism of language depends on the segregation of a temporal sequence to the dominant hemisphere together with a spatial access to engrams in the non-dominant. The differentiation of functions (language) depends of subtle callosal connections into the two hemispheres, which occurs as a result of a dysynchrony of their development ${ }^{21}$. If this segregation phenomenon does not happen properly, it could arise variations in the inter-hemispheric and subsequent intra-hemispheric adjustments originating the psychotic symptoms ${ }^{21}$. The reported cases of CCA with psychosis reinforce this hypothesis. However, neither all cases of CCA are accompanied by psychotic symptoms. Moreover, there are reports of CCA without specific deficits in inter-hemispheric transfer ${ }^{22}$, and there is also one report questioning that the corpus callosum is necessary for the normal development of specific language functions ${ }^{23}$. Soma et al. ${ }^{22}$ postulated that CCA without specific deficits in inter-hemispheric transfer the following mechanisms could be responsible for such compensation; (1) bilateral development of language function, (2) exploitation of extracallosal commissure fibers such as the anterior commissure. It is therefore unlikely that CCA alone could account for the schizophrenia in this case. Moreover, in patients with metachromatic leukodystrophy, psychosis only occurs if the cortical white matter is affected in early adulthood. Lesions developing before this are not associated with psychosis $^{24}$.

Apparently, a small subset of patients with schizophrenia may have obvious anomalies of the CC, and, although this gross developmental anomaly are not representative of schizophrenia, the higher incidence of psychotic symptoms in such patients may suggest that subtle structural or developmental anomalies of the $\mathrm{CC}$ might be present in other patients ${ }^{25}$. There is some evidence that the greater the degree of brain abnormalities in schizophrenia (eg ventricular enlargement), the poorer the response to treatment. An additional factor in this case is the very early onset of psychosis. Most of these patients with grossly abnormalities at the CC showed prominent positive symptoms (delusions and hallucinations) and poor response to antipsychotic drugs $5^{5,10,25}$. The diagnosis of agenesis in such patients is usually made accidentally but the diagnosis still remain as schizophrenia, although the DSM-IV diagnosis in these cases is "psychotic disorder due to a general medical condition". 


\section{It is possible that CCA patients constitute a subgroup that a more incisive psychopharmacological approach may be more beneficial, with clozapine been consid- ered as soon as possible.}

\section{REFERENCES}

1. David AS. Callosal transfer in schizophrenia: too much or too little? J Abnorm Psychol 1993;102:573-579.

2. Scheller-Gilkey G, Lewine RRJ. Age at onset and sex differences in corpus callosum area in schizophrenia. Schizophr Res 1999;40:229-235.

3. Motomura N, Satani S, Inaba M. Monozygotic twin cases of the agenesis of the corpus callosum with schizophrenic disorder. Psychiatry Clin Neurosci 2002;56:199-202.

4. Frumin M, Golland P, Kikinis R, et al. Shape differences in the corpus callosum in first-episode schizophrenia and first-episode psychotic affective disorder. Am J Psychiatry 2002;159:866-868.

5. Swayze VW, Andreasen NC, Ehrhardt JC, Yuh WT, Alliger RJ, Cohen GA. Developmental abnormalities of the corpus callosum in schizophrenia. Arch Neurol 1990;47:805-808.

6. Velek M, White LE Jr, Williams JP, Stafford RL, Marco LA. Psychosis in a case of corpus callosum agenesis. Ala Med 1988;58:27-29.

7. Edelstyn NM, Oyebode F, Riddoch MJ, Soppitt R, Moselhy H, George $\mathrm{M}$. A neuropsychological perspective on three schizophrenic patients with midline structural defects. Br J Psychiatry 1997;170:416-421.

8. Filteau MJ, Pourcher E, Bouchard RH, et al. Corpus callosum agenesis and psychosis in Andermann syndrome. Arch Neurol 1991;48:1275-1280.

9. Taylor M, David AS. Agenesis of the corpus callosum: a United Kingdom series of 56 cases. J Neurol Neurosurg Psychiatry 1998;64:131-134.

10. David AS, Wacharasindhu A, Lishman WA. Severe psychiatric disturbance and abnormalities of the corpus callosum: review and case series. J Neurol Neurosurg Psychiatry 1993;56:85-93.

11. Lewis SW, Reveley MA, David AS, Ron MA. Agenesis of the corpus callosum and schizophrenia: a case report. Psychol Med 1988;18:341-347.
12. Del-Ben CM, Vilela JAA, Crippa JAS, Hallak JEC, Labate CM, Zuardi AW. Test-retest reliability of the Structured Clinical Interview for DSMIV - Clinical Version (SCID-CV) translated into Portuguese. Rev Bras Psiquiatr 2001;23:156-159.

13. American Psychiatric Association. Diagnostic and statistical manual of mental disorders. 4.Ed. Washington, DC: American Psychiatric Association, 1994:314-315.

14. Jacobsen LK, Giedd JN, Rajapakse JC, et al. Quantitative magnetic resonance imaging of the corpus callosum in childhood onset schizophrenia. Psychiatry Res 1997;68:77-86.

15. Bigelow L, Rosenthal R. Schizophrenia and the corpus callosum. Lancet 1972;1:694.

16. Coger RW, Serafetinides EA.Schizophrenia, corpus callosum, and interhemispheric communication: a review. Psychiatry Res 1990;34:163-184.

17. Woodruff PW,Mcmanus I C,David AS. Meta-analysis of corpus callosum size in schizophrenia. J Neurol Neurosurg Psychiatry 1995;58:457-461.

18. Davi AS. Schizophrenia and the corpus callosum: developmental, structural and functional relationships. Behav Brain Res 1994;64:203-211.

19. Endrassa T, Mohr B, Rockstroh B. Reduced interhemispheric transmission in schizophrenia patients: evidence from event-related potentials. Neurosci Letters 2002;320:57-60.

20. Nasrallah HA. Neuropathology of the corpus callosum in schizophrenia. Br J Psychiatry 1982;141:99-100.

21. Crow TJ. Schizophrenia as a transcallosal misconnection syndrome Schizophr Res 1998;30:111-114.

22. Soma Y, Sugishita M, Maruyama S, Yamamoto K, Kawamura M, Okayama K. Interhemispheric visual information transfer in callosal agenesis. No To Shinkei 1989;41:149-155.

23. Jeeves MA, Temple CM. A further study of language function in callosal agenesis. Brain Lang 1987;32:325-235.

24. Hyde HM, Ziegler JC, Weinberger DR. Psychiatric disturbances in metachromatic leukodystrophy. Insights into the neurobiology of psychosis. Arch Neurol;49:401-406.

25. Crippa JAS, Sanches RF, Hallak JEC, Araújo Jr D, Santos AC, Zuardi AW. Lipoma adhered to the corpus callosum in a schizophrenic patient with severe positive symptoms that responded to clozapine. Acta Neuropsychiatrica 2002;14:36-38. 